\title{
Impact of Drought Stress on Grains Filling in Rice and its Management: A Review
}

\author{
Suraj Panja, Arnab Dutta Gupta, Narottam Dey
}

10.18805/ag.R-2369

\begin{abstract}
Rice (Oryza sativa L.) is the world's single most important staple food source for over half of the world's population, whose demand is expected to increase as human population increases almost exponentially every year. There are different kinds of abiotic and biotic stresses that a rice plant endures. Among the different forms of environmental stresses, drought hampers the production of rice grains notably. The reality of climate change is so stark that more and more droughts are expected to be evident in the distant future. Water, being a requisite for rice cultivation, is gradually becoming a highly limited resource across the earth. In comparison to other cereal crops, rice is more sensitive to the soil water content. Decrease of soil water content or the unavailability of water triggers drought stress in rice. Therefore, the management of drought stress for the growth of rice plants is essential as even moderate stress during reproductive growth may result in a drastic reduction of grain yield. The distinct changes brought about by drought stress not only range from morphological to physiological changes but also from biochemical to molecular changes as well. A number of starch synthesis related enzymes like granule bound starch synthase I (GBSSI), soluble starch synthase Ila (SSIla) play important role in grain filling, which are also affected by limited water under drought environment. Due to water scarcity, the rate of photosynthesis decreases, as a result of which dry matter accumulation decreases, which ultimately affects grain filling in rice. Drought causes delayed flowering as well as spikelet sterility, followed by low grain yield during harvesting. The prevalence of drought over longer periods causes reactive oxygen species to form within the rice plants which subsequently denatures proteins and nucleic acids. In many places where drought continues for longer periods, rice plants die resulting in huge loss of grain yields. The effective strategies that have been adopted involves-the development of stable drought tolerant rice varieties through plant breeding programs, the development of short duration rice cultivars which have short growing cycle and harvesting periods that may help the plant to escape drought, the development of rice plants having deep root system such that it can penetrate the soil to find the available moisture and water required for growth, as well as the development of transgenic drought tolerant rice plants which over express specific genes to withstand drought, are few of the effective management strategies that need special attention. Thus, it can be said that drought management for rice production is a crucial step towards food security and food production in the world. The present discussions will emphasize on the negative impact of drought in rice plants and also discuss possible key management practices that can address the existing and imminent drought related problems on rice plants.
\end{abstract}

Key words: Drought stress, GBSSI, Grain filling, Management, Reactive oxygen species, Yield loss.

Globally rice (Oryza sativa L.) is a major food crop, for production and consumption, comparable to other food crops like wheat (Todaka et al., 2015). In 2013, rice cultivation was recorded from 124 countries around the world andproduction stood at 745 million tons (FAOSTAT). In a recent report (Dar et al., 2020) the effect of drought on food security has been reviewed in Eastern India. Rice acts as a source of staple food for more than three billion people and served as a source of daily calorie intake (Khush, 2005). In rice, both reductions of growth and yield loss occurred due to the effect of drought (Basu et al., 2016). In the farming of rice, water is a necessity which again is a highly limited resource (Wang et al., 2012). Rice is very sensitive to drop in soil water content and also requires plenty of water for production compared to other cereal crops, normally 3,000 to 5,000 liters of water, are required for $1 \mathrm{~kg}$ of rice seeds production which is much higher than wheat and others crops (Singh et al., 2002). Drought is the meteorological event, which implies the absence of rainfall for a period of time, long enough to cause moisture depletion in soil and water deficit with a decrease of water potential in plant tissues (Kramer, 1980). The rice ecosystem mostly suffers
Rice Biotechnology Laboratory, Department of Biotechnology, Visva-Bharati, Bolpur-731 235, West Bengal, India.

Corresponding Author: Narottam Dey, Rice Biotechnology Laboratory, Department of Biotechnology, Visva-Bharati, Bolpur731 235, West Bengal, India.

Email: narottam.dey@visva-bharati.ac.in

How to cite this article: Panja, S., Gupta, A.D. and Dey, N. (2022). Impact of Drought Stress on Grains Filling in Rice and its Management: A Review. Agricultural Reviews. DOI: 10.18805/ag.R-2369.

Submitted: 06-09-2021 Accepted: 14-01-2022 Online: 08-03-2022

from drought at the time of flowering stage in both upland and lowland (Mishra and Chaturvedi, 2018). In rice, drought stress affects in various ways during rice production, which globally affects almost 23 million hectares of rice field, which are rain fed (Serraj et al., 2011). Lacks of proper water supply to the root, high transpiration rates are the main reason of drought stress and it effects growth, development and ultimately the yield (Pandey and Shukla, 2015). Being a water loving crop, rice production gets severely impaired by drought stress; a $15 \%$ to $50 \%$ yield loss has been noted 
depending on the vigour and period of stress given (Srividhya et al., 2011). At the time of reproductive growth, a sharp decline in grain yield occurred when rice plant subjected to even moderate levels of drought stress (Venuprasad et al., 2008). The yield of a grain crop is a function of the rate and duration of accumulation of dry weight in the economically valuable parts of the plant (Rahman and Yoshida, 1985). Besides grain size, the duration and rate of grain filling also determine the final grain weight and thereby contribute greatly to grain productivity (Takai et al., 2005). In two recent reports (Berahim et al., 2021; Kumar et al., 2021) the effect of induced drought was studied on different yield related parameters along with stomatal performances. Four components contribute to potential rice grain yield that are grain weight, grain number per panicle, panicle number per plant andthe ratio of filled grains (Sakamoto and Matsuoka, 2008). It has been documented that grain weight was largely determined by grain filling (Wang et al., 2008). Rice grain filling is nothing but a process of starch accumulation, as starch contributes $80 \%$ to $90 \%$ of the final dry weight of brown rice (Zhu et al., 2011). Grain filling is a process which occurs as a complex series of events, including the relocation of carbohydrates synthesized by photosynthetic organs and biosynthesis of starch from sucrose in the developing endosperm (Peng et al., 2013). The main component of rice endosperm is starch and thus incomplete grain filling is generally due to defects in starch synthesis (Zhu et al., 2011). In hybrid cultivars, the vital reason for fluctuation in grain yield is attributed to poor grain filling of the later-flowering spikelets of rice, which is itself is a serious problem (Yang and Zhang, 2010). As a result of climate change, there is a possibility of reduction of yield, in a limited water resource (Ray et al., 2015). In two independent studies (Melandri et al., 2021 and Panda et al., 2021) reported all the different mechanisms behind the drought tolerance in rice in details. A recent report made by Kumar et al. (2020) showed that drought have a major role in quantity and chemistry of resistant starch content and Glycemic index of rice grain during development. Therefore, research on the grain filling in rice in response to stress is essential for us to increase our understanding to employ strategies to combat drought stress, through which grain weight can be enhanced, consequently increasing the grain yield per plant (Peng et al., 2013). For that reason, basic requirement is to know the mechanism of drought tolerance potentiality of plant for better yield in limited rainfall (Mostajeran and Rahimi, 2009). It can be achieved through development of short duration high yielding lines through breeding or transgenics, which may give better yield under environmental stress (Singh et al., 2012). Considering this significant requirement and lacunae, an initiation was taken in present study where a detailed account has been taken on biochemical basis and mechanism of grain filling during developmental stages and how drought alter the grain filling mechanism. Finally, the possible management practices which can be employed to overcome the effect of drought on grain development stage have been discussed.

\section{Grain filling in rice}

In rice, the flowering stage is vital, as it is the stage when the meiosis cell division starts andafter that panicle initiation starts from flag leaf (Biswal and Kholi, 2013). Grain filling is mainly visible when a milky liquid fills the grains, this is the main reason for the increase of dry weight of the grain (Zhang et al., 2012). Rice grain filling is a process of starch accumulation since starch contributes $80 \%$ to $90 \%$ of the final dry weight of an unpolished grain (Duan and Sun, 2005). Initially from sucrose, biosynthesis of starch takes place in the developing endosperm which in turn determines grain yield and rice quality (Zhu et al., 2011). Roles of several crucial enzymes have been documented in the pathway of starch synthesis and (Tetlow et al., 2004); these are sucrose synthase (SUS), UDP-glucose pyrophosphorylase (UG Pase), ADP-glucose pyrophosphorylase (AGPase) andstarch synthase. Among these Sus 3 is highly specific to the grain (Huang et al., 1996). Starch synthase has been found to exist in two different forms and these are granulebound starch synthase (GBSS) and soluble starch synthase (SSS) (Zhu et al., 2011). GBSSI is also called Waxy $(W x)$, both $W x$ and SSIla are highly specific for grains (Chen et al, 2012). Synthesis of amylopectin is more complicated than amylose and involves all four types of enzymes including AGPase, SSS, Starch branching enzyme (SBE) andstarch de branching enzyme (DBE) (Jeon et al. 2010). It was observed that after 3 days to 15 days from pollination, some phytohormones like Auxin, ABA and Zeatin concentrations notably increased (Abu et al., 2012). Cytokinin levels in rice spikelets are significantly correlated with seed development (Zhang et al., 2009). Negative correlation has been found between levels of ethylene in developing seeds and enzymatic activities linked with starch metabolism eventually leading to poor grain filling, for instance more ethylene levels in developing seeds leads to poor grain filling (Zhang et al, 2009). A detailed description of the metabolic pathways associated with sucrose to starch conversion in developing grain particularly during grain filling stage was recently reported by Jiang et al. (2021). Comparative genomics study through transcriptome profiling among two rice genotypes under mild drought during grain-filling stage was conducted by Liang et al. (2021) and in a suppressed transgenic line of the OsSYT-5 gene, Shanmugam et al. (2021) reported the enhanced photosynthetic rate with reduced stomatal conductance and transpiration under water deficit condition. A diagrammatic flow chart describing the major biochemical pathways associated with grain filling in rice in described in Fig 1.

It was noted that when concentrations of ABA increased, transportation of sucrose into the grains got reduced which lowered the ability of grains to synthesize starch (Bhatia and Singh 2002), surprisingly it was also seen that optimum concentrations of Abscisic acid (ABA) augmented SUS activity (Tang et al, 2009). During embryo development, it 


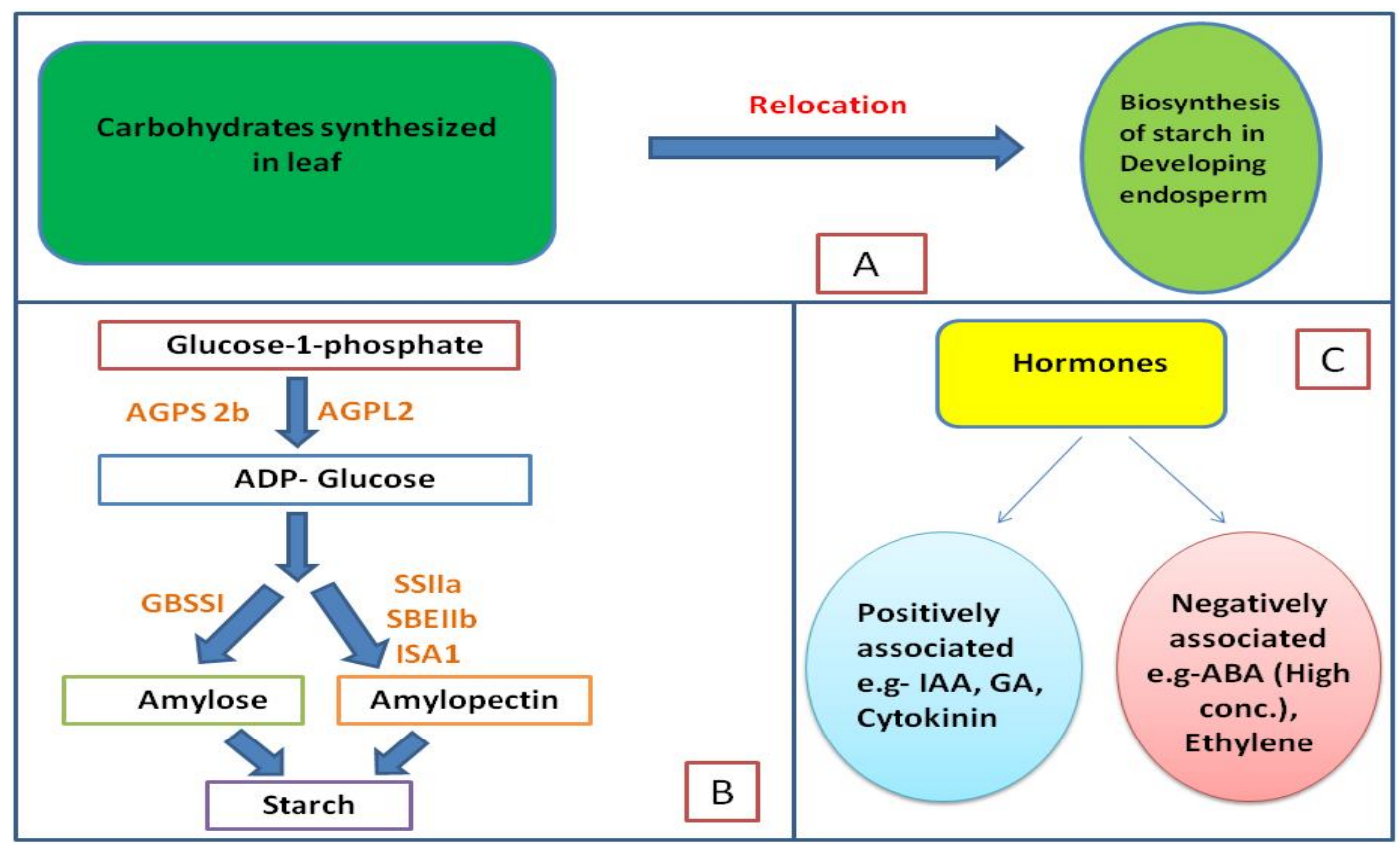

Fig 1: Different aspect of grain filling in rice. A- Carbohydrates translocation from source to sink, B- Major grains specific enzyme unit involved in starch biosynthesis in developing endosperm, C-Major hormones associated with grains filling.

was observed that enhanced Gibberellic acid (GA) concentrations at initial grain filling stages contributed significantly towards rapid enlargement of the embryo (Yang et al, 2002).

\section{Key changes during drought stress in rice}

When drought occurs, usually plant growth rate reduced (Zhu et al, 2004) and poor root development happens with reduced leaf surface (Pandey and Shukla, 2015). Leaf rolling is a common phenomenon and it is used as a criterion for scoring drought tolerance (Kadioglu and Terzi, 2007). As turgor pressure reduces under stress, cell growth severely decreases (Taiz and Zeiger, 2006). Common effects of drought stress are mainly reduction of germination (Swain et al, 2014), inhibition of plant height as well as growth (Sokoto and Muhammod, 2014) and also reduction of panicle number (Bunnag and Pongthai, 2013). Net photosynthesis (Yang et al, 2014) and rate of transpiration are also affected by water stress (Cabuslay et al, 2002) along with stomatal conductance (Singh et al, 2013). It has been proved that drought affects efficiency of water utilization and reduces photosynthetic rate of rice plants. (Yang et al, 2014). Drought reduces photosynthesis in flag leaf by inhibiting PSII activity (Pieters and Souki, 2005). Rubisco enzyme activity sharply decreases during drought, which is the key enzyme of the Calvin cycle (Zhou et al, 2007). Decrease in chlorophyll content has also been reported on drought stressed rice plants (Maisura et al, 2014). A positive correlation is present between relative wWater content (RWC) and water use efficiency (WUE) during drought stress but transpiration rate has negative correlation with WUE (Akram et al, 2013). In cytoplasm, several osmolyte accumulates for osmotic adjustment, among these proline was found to play a major role in drought stress tolerance mechanism (Pandey and Shukla, 2015). It was observed that accumulation of soluble sugars was also induced during drought (Maisura et al, 2014). Proline acts as an osmolyte and it helps for better maintenance and also imparts drought tolerance (Vajrabhaya et al, 2001). Some positively charged molecules like Polyamines (PAs) are also involved in the response to drought (Calzadilla et al, 2014). Reactive oxygen species (ROS) generation is a common phenomenon in response to drought stress (Faize et al, 2011), which includes super oxide radical and others free radicals like hydrogen peroxide and several forms of singlet oxygen. In plants, ROS generation is the main reason for protein, nucleic acid damage and also lipid peroxidation (Pandey et al, 2015). Up-regulation of 5000 genes and down-regulation of more than 6000 genes were observed in rice during drought period as reported (Maruyama et al, 2014). Up regulation of DREB transcription factors in response to drought also play major role in $A B A$-independent pathway, particularly two transcription factors, OsDREB2A and OsDREB2B expression are in high levels during water stress (Matsukura et al, 2010). The OREB1bZIP-type transcription factor also regulates the $A B A-d e p e n d e n t$ pathway in rice (Hong et al, 2011). A summary on overall impact of drought stress on rice plant is presented in Fig 2.

\section{Impact of drought on grains filling}

Three phases during rice plant development that have an impact on grain yield are: Vegetative, reproductive and ripening stages in which drought conditions cause spikelet sterility and unfilled grains (Ndjiondjop et al, 2010). It was 
found that drought stress impaired seed germination and early seedling growth, reduced plant growth and development in the vegetative phase, delayed flowering at the reproductive phase anddecreased the rate of grain filling (Ndjiondjop et al, 2010). Due to water stress, photosynthesis in leaf and flag leaf gets reduced which affects grain filling and which results in low yield in rice (Pandey and Shukla, 2015). During drought stress, reduction of seeds setting was observed with grain size and weight, due to spikelet sterility (Raman et al, 2012). During booting stage, drought stress can effect in various ways (Pantuwan et al, 2002), like floret initiation is interrupted by flowering in terminal periods, resulting in slow grain filling and spikelet sterility, eventually causing low grain weight and as a consequence of which poor paddy yield (Pandey and Shukla, 2015). Reduction in grain yield due to drought occurs probably by decreased grain filling period (Shahryari et al, 2008) along with disruption of leaf and gas exchange properties and the most important grain filling, source and sink translocation also gets affected due to drought stress (Farooq et al, 2009). Water stress can decrease pollen viability by degrading starch of pollen, as result of which pollens grains fail to fertilize the egg (Liu et al, 2006). Sterile panicles increase due to drought in booting phase (Pantuwan et al, 2002) and mild drought in grain filling stage can decrease yield upto $14.7 \%$ (Cai et al, 2006), whereas upto $52 \%$ yield loss was observed due to severe drought during grain filling (Yambao and Ingraml, 1988). In drought stressed tice plants, it was observed that ethylene concentration increases in the rice grain at the early grain-filling stage but decreases during grain development (Yang et al, 2004). Significant yield devastation occurred when water stress was perceived during flowering stage (Yang et al, 2004). Since drought can directly affect flowering, it also results in abortion of flower and one of the major causes for unfilled grain formation and grain abscission (Hsiao et al, 1976). High percentages of unfilled grains were also noted due to drought during reproductive growth stage (Davatgar et al, 2009). This happens because of reduction of assimilate translocation towards tiller of the plant (Rahman et al, 2002). Key enzymes which played an important role in active grain filling process includes enzymes like invertases, sucrose synthase, ADP glucose pyrophosphorylase (AGPase) andstarch synthase as well as the starch branching and the debranching enzymes all of which are affected by drought stress (Sheoran and Saini, 1996). Delayed in flowering time due to water stress was found to be closely associated with filling of grains that ultimately hampered the crop yielding (Pantuwan et al, 2002).

\section{Management of drought stress for better grains filling and yield}

\section{Management through transgenic rice}

One of the modern management strategies for drought stress is the development of transgenic rice. In such transgenic rice, over expression of OsDREB2A and OsDREB2B genes have been found to increase drought tolerance (Cui et al, 2011). ROS accumulation and its subsequent modulation by manganese superoxide dismutase, an anti-oxidant enzyme encoded by transgenic rice plants over expressing the gene $m n S O D$ have resulted in superior osmotic tolerance (Wang et al, 2005). Several traits of rice which include spikelet fertility, grain filling and major yield traits like panicle number per plant, grain number per plant can be achieved through cultivation of transgenic rice plants over expressing NAC5 (Jeong et al, 2013). Drought tolerant transgenic rice plants over expressing OsOAT have also increased heading than normal rice, in response to drought during panicle heading stage (You et al, 2012). In transgenic rice, it was seen that grain yield was

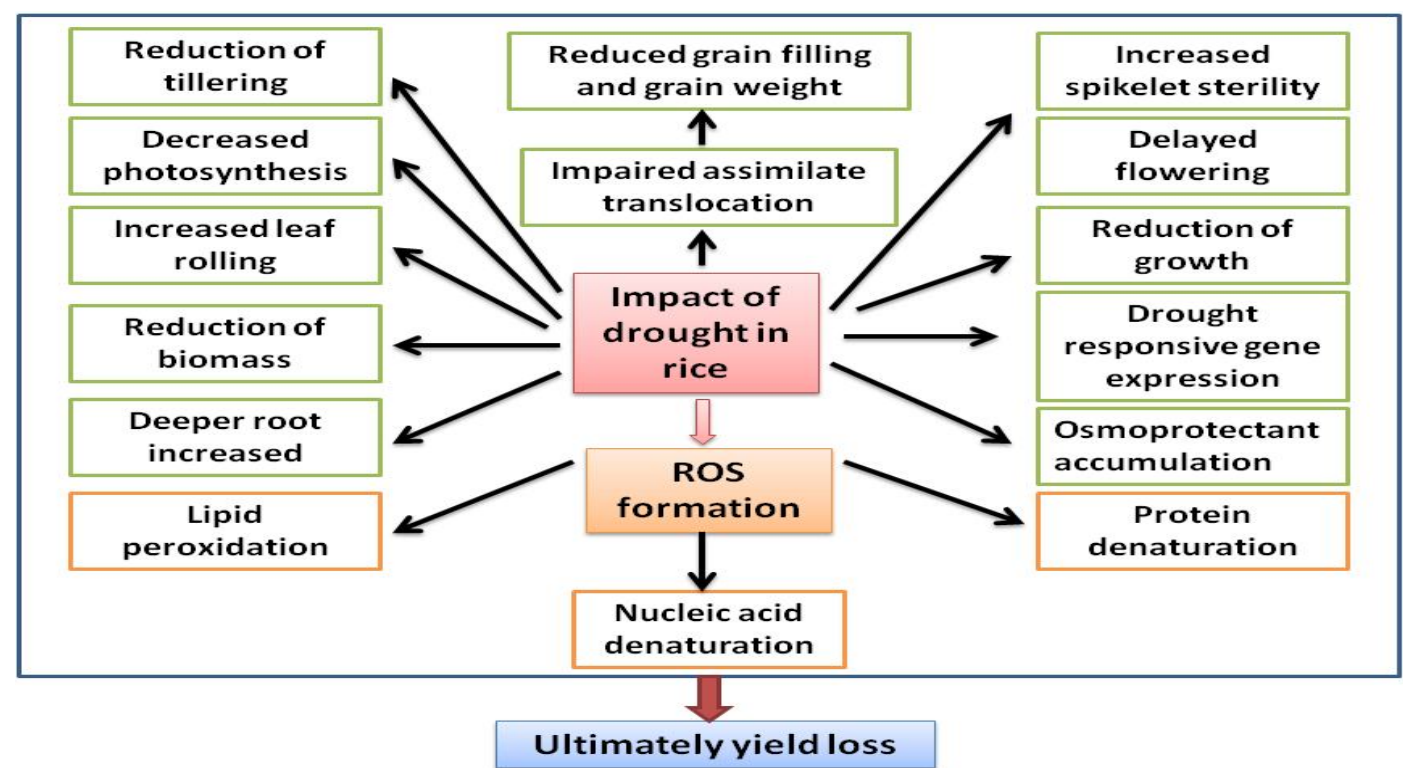

Fig 2: Overall impact of drought stress on rice plant. 


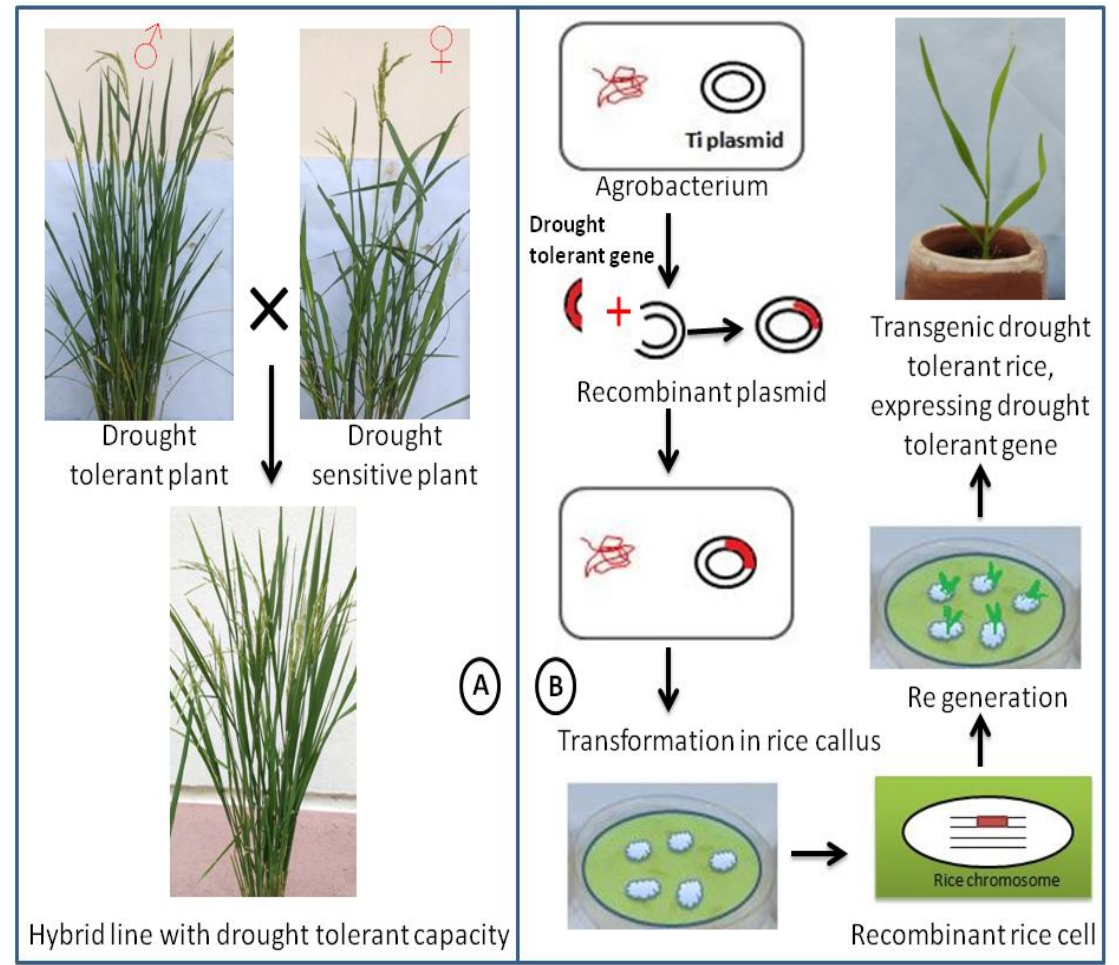

Fig 3: General approach of drought stress management, A- Breeding for drought tolerant hybrid rice production, B-Drought tolerant transgenic rice development.

high through high grain filling during drought condition in field on the time of heading and this was observed as a result of over expression of $A P 37$ gene along with other transcription factor, AP2/ERF (Oh et al, 2009). Improvement of drought tolerance by silencing OsSYT-5 gene has been reported by Shanmugam et al. (2021).

\section{Management through hybridization}

The first step towards development of drought tolerant crop plants is the identification of genetic variation responsible for drought resistance (DR) but improvement of such desirable DR attributes in crop plants is a critical challenge for plant breeders and crop physiologists since the drought resistance involves a complex genetic trait with multiple pathways (Basu et al, 2016). Drought management is possible through development of short cycle hybrid rice, with very fast reproductive cycle and which are able to produce seeds before on set of drought stress (Yue et al, 2006). Farming of such short duration cultivars is effective as it has short grain filling period and these rice lines possessing various adaptive mechanisms which helps to escape terminal drought occurring during the reproductive stage. Hybrid rice with long flag leaf has great positive impact on yield under drought stress (Kumar et al, 2021). Hybrid varieties can tolerate drought by controlling stomatal opening and water conduction in root by producing Spermidine (SPD) (Berahim et al, 2021).

An overview on general approach of drought stress management in rice is presented in Fig 3.

\section{CONCLUSION AND FutuRE RESEARCH PERSPECTIVE}

Development of drought tolerance in crop plants such as rice is tricky and challenging task that involves comprehensive in-depth understanding of the various characters that govern grain filling for better yield, under drought conditions. These characters range from morphological to physiological as well as include characters that range from molecular to biochemical. It has been widely observed that variations of different components in wild species of rice lines which grow in drought prone regions contain genotypes that have evolved and are well adapted as a result of natural selection. These wild species having drought tolerant properties can be introgress in to sensitive line for increased yield potentiality. Also, more investigations are required to understand the interplay of endogenous phytohormones and its optimum concentrations that imparts drought resistance and improves grain filling in rice. Usage of advanced phenotyping platforms for selection of genotypes responsible for drought resistance will help in the identification of Quantitative Trait Loci (QTL) and genomic regions that contribute to drought resistance. There may be a good number of related traits, which govern the grain development collectively under drought stress, identification of which are necessary to understand and establish, which of the traits are primary contributors to grain yield in rice plants. Nevertheless, the practical and promising way of selecting potential rice genotypes through breeding 
programmes is to observe grain yield under drought, a yardstick which will eventually lead to the development of high yielding drought resistant cultivars. In addition to molecular breeding approaches, genetic engineering of regulatory genes, which are responsible for grain filling and high yield will also be essential in future for our food security during water scarcity.

\section{ACKNOWLEDGEMENT}

Authors are grateful to DRDO/LSRB, Government of India, for financial support, in the form of a major research project of 2017(Ref.No-LSRB303) and also UGC Non NET fellowship.

\section{Conflict of interest: None.}

\section{REFERENCES}

Abu-Zaitoon, Y.M., Bennett, K., Normanly, J., Nonhebel, H.M. (2012). A large increase in IAA during development of rice grains correlates with the expression of tryptophan amino transferase OsTAR1 and a grain-specific YUCCA, Physiol Plant. 146: 487-499.

Akram, H.M., Ali, A., Sattar, A., Rehman, HSU., Bibi, A. (2013). Impact of water deficit stress on various physiological and agronomic traits of three basmati rice (Oryza sativa L.) cultivars. J. Anim Plant Sci. 23(5): 1415-1423.

Basu, S., Ramegowda, V., Kumar, A., Pereira, A. (2016). Plant adaptation to drought stress, [version 1; referees: 3 approved] F1000Research, 5(F1000 Faculty Rev): 1554.

Berahim, Z., Dorairaj, D., Omar, M.H., Saud, H.M., Ismail, M.R. (2021). Spermine mediated improvements on stomatal features, growth, grain filling and yield of rice under differing water availability. Scientific Reports. 11(1): pp.1-15.

Bhatia, S. and Singh, R. (2002). Phytohormone-mediated transformation of sugars to starch in relation to the activities of amylases, sucrose metabolizing enzymes in sorghum grain. Plant Growth Regulation. (36): 97-104.

Biswal, A.K. and Kohli, A. (2013). Cereal flag leaf adaptations for grain yield under drought knowledge status and gaps, Mol Breed. (31): 749-766.

Bunnag, S. and Pongthai, P. (2013). Selection of rice (Oryza sativa L.) cultivars tolerant to drought stress at the vegetative stage under field conditions. Am. J. Plant Sci. 4(9): 1701-1708.

Cabuslay, G.S., Ito, O., Alejal, A.A. (2002). Physiological evaluation of responses of rice (Oryza sativa L.) to water deficit, Plant Sci. 163(4): 815-827.

Cai, Y., Wang, W., Zhu, Z., Zhang, Z., Langm, Y., Zhu, Q. (2006). Effects of water stress during grain-filling period on rice grain yield and its quality under different nitrogen levels. (17): 1201-1206.

Calzadilla, P.I., Gazquez, A., Maiale, S.J., Rodriguez, A.A., Ruiz, O.A., Bernardina, M.A. (2014). Polyamines as Indicators and Modulators of the Abiotic Stress in Plants. In: Plant Adaptation to Environmental Change: Significance of Amino Acids and Their Derivatives. CABI, Wallingford, UK. 109-128.

Chen, Y., Wang, M., Pieter, B.F. (2012). Molecular and environmental factors determining grain quality in rice, Ouwerkerk Food and Energy Security. 1(2): 111-132.
Cui, M., Zhang, W., Zhang, Q., Xu, Z., Zhu, Z., Duan, F. (2011). Induced over-expression of the transcription factor OsDREB2A improves drought tolerance in rice, Plant Physiol Biochem. (49): 1384-1391.

Dar, M.H., Waza, S.A., Shukla, S., Zaidi, N.W., Nayak, S., Hossain, M., Kumar, A., Ismail. A.M., Singh, U.S., (2020). Drought tolerant rice for ensuring food security in Eastern India. Sustainability. 12(6): p.2214.

Davatgar, N., Neishabouri, M.R., Sepaskhah, A.R., Soltani, A. (2009). Physiological and morphological responses of rice (Oryza sativa L.) to varying water stress management strategies. Int. J. Plant Prod. 3(4): 19-32.

Duan, M. and Sun, S. (2005). Profiling the expression of genes controlling rice grain quality, Plant Mol Bio. (59): 165-178.

Faize, M., Burgos, L., Faize, L., Piqueras, A., Nicolas, E., BarbaEspin, G., Clemente-Moreno, M.J., Alcobendas, R., Artlip, T., Hernandez, J.A. (2011). Involvement of cytosolic ascorbate peroxidase and $\mathrm{Cu} / \mathrm{Zn}$ superoxide dismutase for improved tolerance against drought stress, J Exp Bot. 62(8): 2599-2613.

FAOSTAT- Food and Agriculture Organization of the United Nations (Free data base 2013).

Farooq, M., Wahid, A., Lee, D.J. (2009). Exogenously applied polyamines increase drought tolerance of rice by improving leaf water status, photosynthesis and membrane properties, Acta Physiol Plant. 31(5945): 937-945.

Hong, J.Y., Chae, M.J., Lee, L.S., Lee, Y.N., Nam, M.H., Kim, D.Y. (2011). Phosphorylation mediated regulation of a rice $A B A$ responsive element binding factor Phytochemistry. 72: 27-36.

Hsiao, T.C., Fereres, E., Acvedo, E., Henderson, W. (1976). Water Stress and Dynamics of Growth and Yield of Crop Plants, Springer. pp: 281-305.

Huang, J.W., Chen, J.T., Yu, W.P., Shyur, L.F., Wang, A.Y., Sung, H.Y. (1996). Complete structures of three rice sucrose synthase isogenes and differential regulation of their expressions, Biosci Biotechnol Biochem. 60: 233-239.

Jeon, J.S., Ryoo, N., Hahn, T.R., Walia, H., Nakamura, Y. (2010). Starch biosynthesis in cereal endosperm, Plant Physiol Biochem. 48: 383-392.

Jeong, J.S., Kim, Y.S., Redillas, M.C.F.R., Jang, G., Jung, H., Bang, S.W. (2013). OsNAC5 over expression enlarges root diameter in rice plants leading to enhanced drought tolerance and increased grain yield in the field, Plant Biotech nol J. 11: 101-114.

Jiang, Z., Chen, Q., Chen, L., Yang, H., Zhu, M., Ding, Y., Li, W., Liu, Z., Jiang, Y., Li, G. (2021). Efficiency of sucrose to starch metabolism is related to the initiation of inferior grain filling in large panicle rice. Frontiers in Plant Science. p.1944.

Kadioglu, A. and Terzi, R. (2007). A dehydration avoidance mechanism: Leaf rolling. Bot Rev. 73(4): 290-302.

Khush, G.S. (2005). What it will take to feed 5.0 billion rice consumers in 2030. Plant Mol Biol. 59(1): 1-6.

Kramer, P.J. (1980). Linking Research to Crop Production, Press New York. pp: 51-62.

Kumar, A., Das, G.K., Barik, M., Panda, A.P., Lal, Baig, M.J., Swain, P. (2020) Effect of Drought stress on Resistant starch content and Glycemic index of rice (Oryza sativa L.) Starch. 72: 11-12. 
Kumar, S., Tripathi, S., Singh, S.P., Prasad, A., Akter, F., Syed, M.A., Badri, J., Das, S.P., Bhattarai, R., Natividad, M.A., Quintana, M., (2021). Rice breeding for yield under drought has selected for longer flag leaves and lower stomatal density. Journal of Experimental Botany. 72(13): pp. 4981-4992.

Liang, Y., Tabien, R.E., Tarpley, L., Mohammed, A.R., Septiningsih, E.M. (2021). Transcriptome profiling of two rice genotypes under mild field drought stress during grain-filling stage. AoB Plants. 13(4): plab043.

Liu, J.X., Liao, D.Q., Oane, R., Estenor, L., Yang, X.E., Li, Z.C., Bennett, J. (2006). Genetic variation in the sensitivity of anther dehiscence to drought stress in rice, Field Crops Res. (97): 87-100.

Maisura Chozin, M.A., Lubis, I., Junaedinand, A., Ehara, H. (2014). Some physiological character responses of rice under drought conditions in a paddy system, J Int Soc Southeast Asian Agric Sci. 20(1): 104-114.

Maruyama, K., Urano, K., Yoshiwara, K., Morishita, Y., Sakurai, N., Suzuki, H. (2014). Integrated analysis of the effects of cold and dehydration on rice metabolites, phytohormones andgene transcripts, Plant Physiol. (164): 1759-1771.

Matsukura, S., Mizoi, J., Todaka, D., Ito, Y., Maruyama, K. (2010). Comprehensive analysis of rice DREB2-type genes that encode transcription factors involved in the expression of abiotic stress responsive genes. Mol Genet, Genomics. (283): 185-196.

Melandri, G., AbdElgawad, H., Floková, K., Jamar, D.C., Asard, H., Beemster, G.T., Ruyter-Spira, C., Bouwmeester, H.J. (2021). Drought tolerance in selected aerobic and upland rice varieties is driven by different metabolic and anti oxidative responses. Planta. 254(1): pp.1-16.

Mishra, B.K. and Chaturvedi, G.S. (2018). Flowering Stage Drought Stress Resistance in Upland Rice in Relation to Physiological, Biochemical Traits and Yield, I J of Currnt Micro Bio and Appld sc. 2(7): 2319-7706.

Mostajeran, A. and Rahimi, E.V. (2009). Effects of Drought Stress on Growth and Yield of Rice (Oryza sativa L.) Cultivars and Accumulation of Proline and Soluble Sugars in Sheath and Blades of Their Different Ages Leaves, AmEuras. J. Agric. and Environ. Sci. 5 (2): 264-272.

Ndjiondjop, M.N., Cisse, K., Futakuchi, M., Lorieux, B., Manneh, R., Fatondji, B. (2010). Effect of drought on rice (Oryza spp.) genotypes according to their drought tolerance level. Second Africa Rice Congress: Innovation and Partnerships to Realize Africa's Rice Potential in Mali, 2010.

Oh, S.J., Kim, Y.S., Kwon, C.W., Park, H.K., Jeong, J.S., Kim, J.K. (2009). Over expression of the transcription factor AP37 in rice improves grain yield under drought conditions. Plant Physiol. (150): 1368-1379.

Panda, D., Mishra, S.S., Behera, P.K. (2021). Drought tolerance in rice: Focus on recent mechanisms and approaches. Rice Science. 28(2): 119-132.

Pandey, V. and Shukla, A. (2015). Acclimation and Tolerance Strategies of Rice under Drought Stress, Rice Sc. 22(4): 147-161.
Pantuwan, G., Fukai, S., Cooper, M., Rajatasereekul, S., Toole, J.C. (2002). Yield responses of rice (Oryza sativa L.) genotypes to drought under rainfed lowlands: 2 . Selection of drought resistant genotypes, Field Crops Res. 73(2/3): 169-180.

Peng, T., Sun, H., Du, Y., Zhang, J., Li, J. (2013). Characterization and Expression Patterns of microRNAs Involved in Rice Grain Filling, PLoS One. 8(1): e54148.

Pieters, A.J. and Souki, S.E. (2005). Effects of drought during grain filling on PSIl activity in rice, J Plant Physiol. 162(8): 903911.

Rahman, M.S. and Yoshida, S. (1985). Effect of Water Stress on Grain Filling in Rice, Soil Sci and Plant Nutri. 31(4): 497511.

Rahman, M.T., Islam, M.T., Islam, M.O. (2002). Effect of water stress at different growth stages on yield and yield contributing characters of transplanted Aman rice, Pak. J. Biol. Sci. 5(2): 169-172.

Raman, A., Verulkar, S.B., Mandal, N.P., Variar, M., Shukla, V.D., Dwivedi, J.L., Singh, B.N., Singh, O.N., Swain, P., Mall, A.K., Robin, S., Chandrababu, R., Jain, A., Ram, T., Hittalmani, S., Haefele, S., Piepho, H.P., Kumar, A. (2012). Drought yield index to select high yielding rice lines under different drought stress severities, Rice. 5(31): 1-12.

Ray, D.K., Gerber, J.S., MacDonald, G.K., West, P.C. (2015). Climate variation explains a third of global crop yield variability, Nature Communication. (6): 59-89.

Sakamoto, T. and Matsuoka, M. (2008). Identifying and exploiting grain yield genes in rice, Curr op in plant bio. (11): 209214.

Serraj, R., McNally, K.L., Slamet-Loedin, I., Kohli, A., Haefele, S.M., Atlin, G., Kumar, A. (2011). Drought resistance improvement in rice: An integrated genetic and resource management strategy. Plant Prod Sci. 14(1): 1-14.

Shahryari, R., Gurbanov, E., Gadimov, A., Hassanpanah, D. (2008). Tolerance of 42 bread wheat genotypes to drought stress after anthesis, Pak J Biol Sci. 11(10): 1330-1335.

Shanmugam, S., Boyett, V.A., Khodakovskaya, M. (2021). Enhancement of drought tolerance in rice by silencing of the OsSYT-5 gene. PloS One. 16(10): e0258171.

Sheoran, I.S., Saini, H.S. (1996). Drought-induced male sterility in rice: Changes incarbohydrate levels and enzyme activities associated with the inhibition of starch accumulation in pollen. Sexual Plant Reprod. 9(3): 161-9.

Singh, A., Sengar, K., Sengar, R.S. (2013). Gene regulation and biotechnology of drought tolerance in rice, Int J Biotechnol Bioeng Res. 4(6): 547-552.

Singh, A.K., Choudhury, B.U., Bouman, B.A.M. (2002). Water-wise rice production in Proceedings of the international workshop on water-wise rice production (Los Baños, Philippines: International Rice Research Institute): 237-248.

Singh, C.M., Kumar, B., Mehandi, S., Chandra, K. (2012). Effect of Drought Stress in Rice: A Review on Morphological and Physiological Characteristics, Trends in Bio sci. 5(4): 261-265.

Sokoto, M.B., Muhammad, A. (2014). Response of rice varieties to water stress, Nigeria J Biosci Med. 2(1): 68-74. 
Srividhya, A., Vemireddy, L.R., Sridhar, S., Jayaprada, M., Ramanarao, P.V., Hariprasad, A.S., Reddy, H.K., Anuradha, G., Siddiq, E. (2011). Molecular mapping of QTLs for yield and its components under two water supply conditions in rice (Oryza sativa L.), J. Crop Sci. Biotech. 14(1): 45-56.

Swain, P., Anumalla, M., Prusty, S., Marndi, B.C., Rao, G.J.N. (2014). Characterization of some Indian native land race rice accessions for drought tolerance at seedling stage, Aust J Crop Sci 8(3): 324-331.

Taiz, L. and Zeiger, E. (2006). Plant Physiology. 4th edn.

Takai, T., Fukuta, Y., Shiraiwa, T., Horie, T. (2005). Time-related mapping of quantitative trait loci controlling grain-filling in rice (Oryza sativa L.), J Exp Bot. (56): 2107-2118.

Tang, T., Xie, H., Wang, Y.X., Lu, B., Liang, J.S. (2009). The effect of sucrose and abscisic acid interaction on sucrose synthase and its relationship to grain filling of rice (Oryza sativa L.), J of Exp Bot. (60): 2641-2652.

Tetlow, I., Morell, M., Emes, M. (2004). Recent developments in understanding the regulation of starch metabolism in higher plants, J of Exp Bot. (55): 2131-2145.

Todaka, D., Shinoz, K., Yamaguchi, K. (2015). Recent advances in the dissection of drought stress regulatory networks and strategies for development of drought-tolerant transgenic rice plants, Fronti Plant sc. (84):1-6.

Vajrabhaya, M., Kumpun, W., Chadchawan, S. (2001). The solute accumulation: The mechanism for drought tolerance in RD23 rice (Oryza sativa L.) lines, Sci Asia. (27): 93-97.

Venuprasad, R., Cruz, M.T., Amante, M., Magbanua, R., Kumar, A., Atlin, G.N. (2008). Response to two cycles of divergent selection for grain yield under drought stress in four rice breeding populations, Field Crop Res. 107(3): 232-44.

Wang, E., Wang, J., Zhu, X., Hao, W., Wang, L., Li, Q., Zhang, L., He, W., Lu, B., Lin, H., Ma, H., Zhang, G., He, Z. (2008). Control of rice grain-filling and yield by a gene with a potential signature of domestication, Nat Genet. (40): 1370-1374.

Wang, F.Z., Wang, Q.B., Kwon, S.Y., Kwak, S.S., Su, W.A. (2005). Enhanced drought tolerance of transgenic rice plants expressing manganese superoxide dismutase, J Plant Physio. I(162): 465-472.

Wang, J.H., Geng, L.H., Zhang, C.M. (2012). Research on the weak signal detecting technique for crop water stress based on wavelet de noising, Adv Mat Res. 424(425): 966-970.

Yambao, E.B. and Ingram, K.T. (1988). Drought stress index for rice, Philippines J Crop Sci (1): 105-111.
Yang, J. and Zhang, J. (2010). Grain-filling problem in 'super' rice. $J$ of Exp Bot. (61): 1-5.

Yang, J., Zhang, J., Wang, Z., Xu, G., Zhu, Q., (2004). Activities of key enzymes in sucrose-to-starch conversion in wheat grains subjected to water deficit during grain filling, Plant Physiol (135): 1621-9.

Yang, J., Zhang, J., Wang, Z., Zhu, Q., Liu, L. (2002). Abscisic acid and cytokinins in the root exudates and leave and their relationship to senescence and remobilization of carbon reservesin rice subjected to water stress during grain filling, Planta. 215(4):645-52.

Yang, P.M., Huang, Q.C., Qin, G.Y., Zhao, S.P., Zhou, J.G. (2014). Different drought-stress responses in photosynthesis and reactive oxygen metabolism between autotetraploid and diploid rice, Photosynthetica. 52(2): 193-202.

You, J., Hu, H., Xiong, L. (2012). An ornithine $\delta$-amino transferase gene OsOAT confers drought and oxidative stress tolerance in rice, Plant Sci. (197): 59-69.

Yue, B., Xue, W., Xiong, L., Yu, X., Luo, L., Cui, K., Jin, D., Xing, Y., Zhang, Q. (2006). Genetic basis of drought resistance at reproductive stage in rice: Separation of drought tolerance from drought avoidance, Genet. (172): 12131228.

Zhang, H., Li, H., Yuan, L., Wang, Z., Yang, J., Zhang, J. (2012). Post-anthesis alternate wetting and moderate soil drying enhances activities of key enzymes in sucrose-to-starch conversion in inferior spikelets of rice, J Exp Bot. (63): 215-227.

Zhang, H., Tan, G., Yang, L., Yang, J., Zhang, J., Zhao, B. (2009). Hormones in the grains and roots in relation to postanthesis development of inferior and superior spikelets in japonica/indica hybrid rice, Plant Physiology and Biochemistry. (47): 195-204.

Zhou, Y., Lam, H.M., Zhang, J. (2007). Inhibition of photosynthesis and energy dissipation induced by water and high light stresses in rice, J Exp Bot. 58(5): 1207-1217.

Zhu, G., Ye, N., Yang, J., Peng, X., Zhang, J. (2011). Regulation of expression of starch synthesis genes by ethylene and $A B A$ in relation to the development of rice inferior and superior spikelets, J of Exp Bot. 11(62): 3907-3916.

Zhu, Q.H., Ramm, K., Shivak, K.R., Dennis, E.S., Upadhyaya, N.M. (2004). The anther indehiscence1 gene enconding a single MYB domain protein is involved in another development in rice, Plant Physiol. (135): 1514-1520. 